\title{
Mechanical size limitation and life-history strategy of an intertidal seaweed
}

\author{
Bryce D. Wolcott* \\ Department of Integrative Biology, 3060 Valley Life Sciences Building, University of California, Berkeley, \\ California 94720-3140, USA
}

\begin{abstract}
Ocean waves impose large hydrodynamic forces on organisms living on rocky shores. Many intertidal organisms are structurally flexible, and the effect of this flexibility on the mechanical forces they experience is poorly understood. In addition, organisms in the rocky intertidal zone are generally much smaller than those in subtidal or terrestrial habitats. This study examined the influence of structural flexibility on the forces imposed by waves on the intertidal seaweed Pelvetiopsis limitata, including the potential for a mechanical size constraint on this species. A mechanical model of a seaweed on a wave-swept shore was developed on the basis of laboratory measurements of algal characteristics. Computer simulations predict that flexibility dramatically increases the forces imposed on the algae, particularly for large individuals. Along with field data on wave conditions and algal tenacity, this indicates that large algae are more likely to be dislodged than small ones throughout the year, and that very large individuals are expected to survive only during the summer and early fall. Measurements of thallus size in a population of $P$. limitata during a $2 \mathrm{yr}$ period corroborated these model predictions. Algae in the field developed reproductive structures during the summer and early fall, when they were the largest and waves were the smallest. Thus, P. limitata exhibits a life-history strategy in which it grows large when seasonal wave conditions permit, and reproduces before becoming dislodged by large winter waves, mitigating the reproductive consequences of a mechanical size constraint.
\end{abstract}

KEY WORDS: Disturbance - Waves · Algae · Biomechanics · Rocky shore · Size · Hydrodynamics · Flexibility $\cdot$ Life history

Resale or republication not permitted without written consent of the publisher

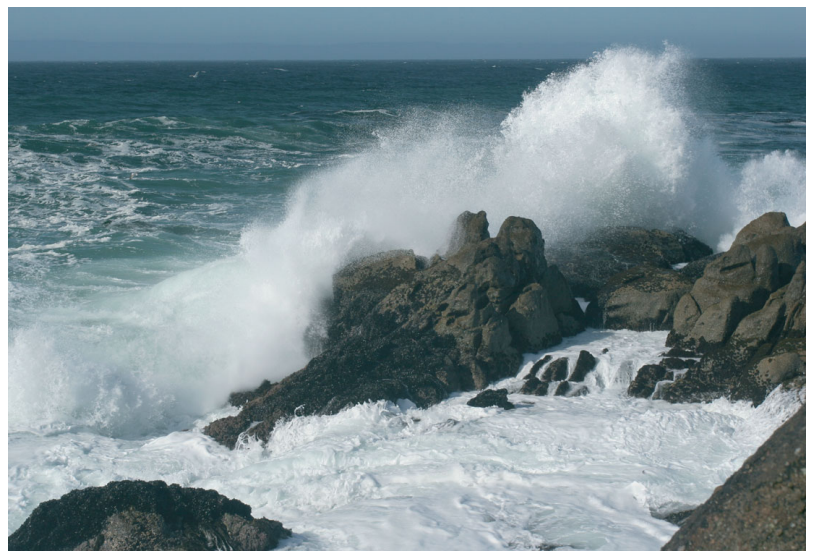

Wave action on rocky shores imposes mechanical forces that limit the size, and influence the life-history strategies, of flexible organisms living there.

Photo: Luke Miller

\section{INTRODUCTION}

Organisms living in the rocky intertidal zone can be subjected to large hydrodynamic forces beneath breaking waves (Koehl 1977, Denny 1985, 1995, Gaylord 2000). Waves are an ecologically important agent of disturbance on the rocky shore, clearing valuable space on the rock for new recruits by damaging or dislodging residents (e.g. Dayton 1971, Sousa 1984). Many intertidal organisms, or their attachments to the rock, are flexible (e.g. seaweeds, mussels, stalked ascidians), and several studies have aimed to investigate the influence of this flexibility on the mechanics of these plants and animals (e.g. Koehl 1977, 1984, Friedland \& Denny 1995, Denny \& Gaylord 2002). In some 
cases, the spring-like properties of the tissues in these organisms, and their structural flexibility, may act to reduce the large hydrodynamic forces imposed on them by crashing waves. Reconfiguration or stretching in rapid fluid flow may ultimately reduce the force transmitted to the site of attachment (Koehl \& Wainwright 1977, Koehl 1998). A mathematical model describing the forces on flexible organisms in flow (Denny et al. 1998), however, indicates that the inertia of organisms tossed back and forth in the surf may actually increase the tensile forces imposed on their attachments to the rock.

Wave-induced mortality may also impose a mechanical limit on the size of organisms in the rocky intertidal zone. Intertidal organisms are generally small, relative to those in adjacent subtidal or terrestrial habitats, with larger individuals/species often restricted to less exposed areas of the coast (Lewis 1968, Harger 1970, Connell 1972, Paine 1976). In some species, these patterns may be result because large individuals are more likely to become damaged or dislodged by waves. Initial attempts to attribute such a mechanical size limitation to the hydrodynamic forces caused by strong acceleration of the water on exposed rocky shores (Denny et al. 1985, Gaylord et al. 1994) have been called into question by detailed field measurements of flow beneath waves (Gaylord 1999, Denny 1999); nevertheless, inertial forces experienced by flexible intertidal organisms (Denny et al. 1998) may be another mechanism by which the body size of these organisms is constrained. These forces may increase with body mass or volume faster than attachment strength, imposing a mechanical limitation on the size of flexible organisms. Hydrodynamic disturbances that impose this size constraint on rocky shore organisms are seasonally predictable, with the largest and most destructive waves occurring during winter storms (e.g. Sousa 1979, Paine \& Levin 1981). If size is mechanically limited, the magnitude of this limit would thus be predicted to vary seasonally as well, allowing larger individuals to survive during seasons with smaller surf.

Any limitation on body size is likely to have reproductive consequences. Large individuals often contribute disproportionately to the reproductive effort of a population due to their greater maturity (reviewed by Stearns 1976), and lesser internal space constraints on gamete production and storage (reviewed by Sebens 1987). A mechanical constraint on body size may limit an individual's reproductive success, and the reproductive success of the population as a whole. Species living in habitats with temporally predictable disturbance events (e.g. large waves, drought, fire) often reproduce just before such events occur (e.g. Santelices et al. 1980, Ceccarelli 1984, Koehl 1984, 1999, Whelan 1995). If flexible organisms on the rocky shore are mechanically size-limited, they may reduce the reproductive consequences of this size constraint by growing large when conditions permit (during summer and early fall), and reproducing before they are ripped from the rocks by the first winter storms .

In this study I used Pelvetiopsis limitata (Fig. 1A), to investigate the effect of flexibility on the forces imposed on an intertidal organism, and the potential for mechanical size limitation. $P$. limitata is a perennial, brown macroalga, one the most common mid/highintertidal seaweeds between central California and British Columbia (Abbott \& Hollenberg 1976). The life history of this species is simple, relative to other algae,
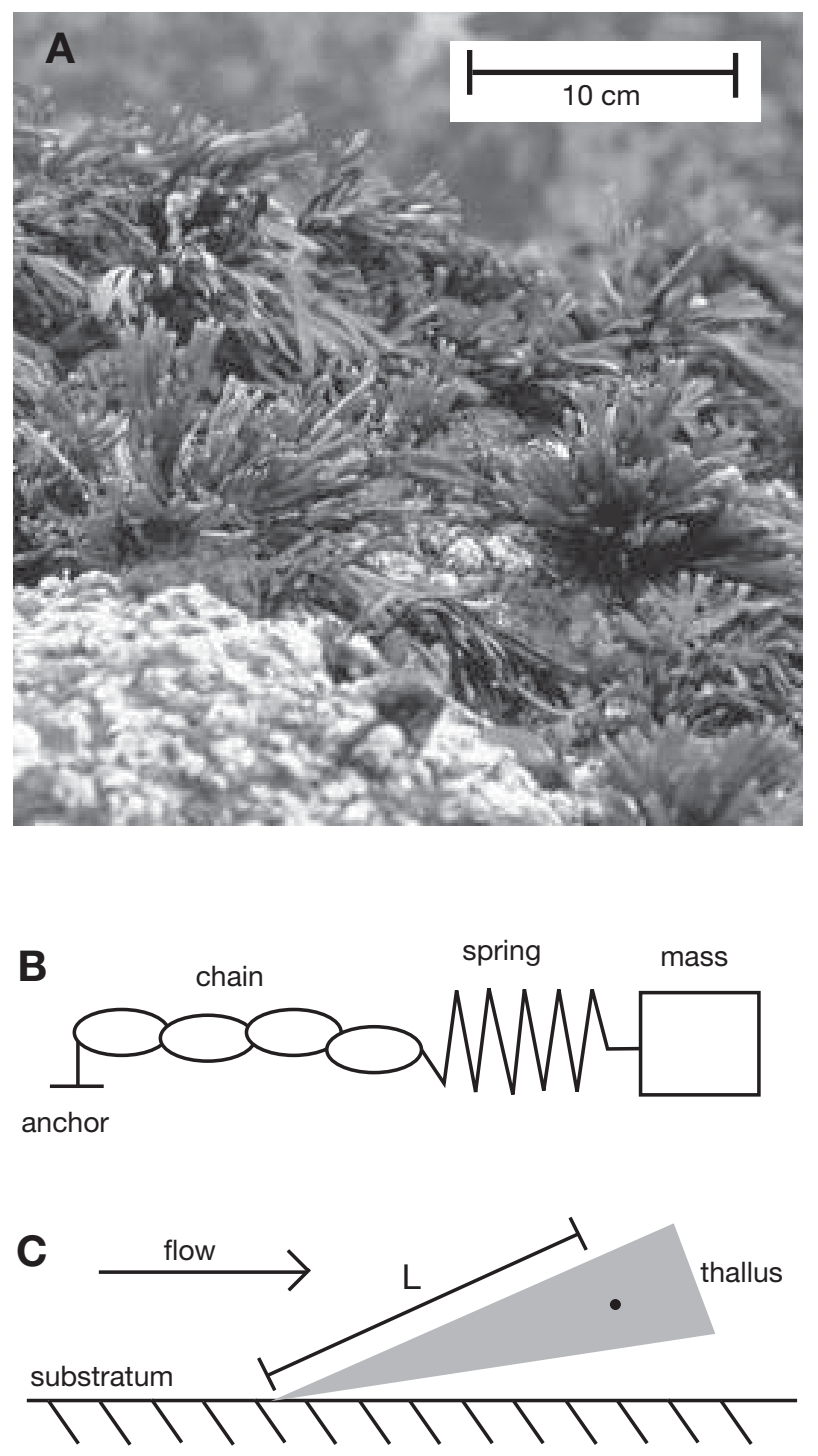

Fig. 1. (A) Pelvetiopsis limitata in the field. (B) Diagram of the mechanical model; see 'Methods: Model' for description. (C) Diagram of an alga compacted by water flow into the shape of a cone; point: center of mass of the thallus, at a distance $L$ from the holdfast ( $L$ is $0.8 \times$ height of the cone) 
as it has no free-living gametophyte (Abbott \& Hollenberg 1976), and its reproductive effort is easily quantified due to the obvious presence or absence of gametecontaining receptacles (Gardner 1913) on the branch tips. The influence of thallus flexibility on the forces imposed on P. limitata, and the potential for hydrodynamic forces to limit the size of this species were examined using computer simulations of a mechanical model. Parameters obtained through field and laboratory measurements of this species, in addition to offshore buoy data describing seasonal wave conditions, were used in the model to predict the scaling of mechanical forces and dislodgement risk with algal size throughout the year. Monthly observations of a population of $P$. limitata in the field were used to test the seasonal patterns of algal size predicted by the model. These observations were also used to determine the seasonality of reproduction relative to wave size.

\section{METHODS}

Model. To estimate the forces imposed on Pelvetiopsis limitata by waves, I used computer simulations of a mechanical model of a deformable alga in flow. The model consists of a mass representing thallus size, attached to a spring with the material properties of algal tissue, hooked to a chain to incorporate the structural flexibility of the thallus, all anchored to the rock via a holdfast (Fig. 1B, Denny et al. 1998). The terms in all equations are defined in Table 1. The motion of the mass $(m)$ in the seaward and shoreward flow beneath waves is determined by Newton's Second Law; thallus acceleration times its mass is equal to the sum of the forces on that mass. In this case, at any instant, those forces are the instantaneous drag $(D)$, the acceleration reaction $(R)$, and tension $(T)$ in the spring and chain. $D$ is a hydrodynamic force due to the velocity of fluid flow relative to the thallus, and given by

$$
D=\frac{1}{2} \rho C_{d} S\left(u-\frac{\mathrm{d} x}{\mathrm{~d} t}\right)\left|u-\frac{\mathrm{d} x}{\mathrm{~d} t}\right|
$$

where $\rho$ is the density of seawater $\left(1026 \mathrm{~kg} \mathrm{~m}^{-3}\right), C_{d}$ is a dimensionless drag coefficient, $S$ is the projected area of the thallus, $u$ is the instantaneous velocity of fluid flow, and $\mathrm{d} x / \mathrm{d} t$ is the velocity of the mass, where $x$ is the position of the mass along the axis of flow, and $t$ is time. Thus, the term $(u-\mathrm{d} x / \mathrm{d} t)$ determines the actual flow velocity experienced by a moving thallus. The origin of the single-axis coordinate system is defined at the anchor (holdfast). A force $(R)$ due to the instantaneous acceleration of the fluid relative to the thallus is given by
Table 1. Terms used in equations

\begin{tabular}{|c|c|}
\hline Term & Definition \\
\hline$v$ & $\begin{array}{l}\text { Kinematic viscosity of water, approximately } 1 \times \\
10^{6} \mathrm{~m}^{2} \mathrm{~s}^{-1} \text { for freshwater in the flume at } 20^{\circ} \mathrm{C}, \\
\text { and } 1.3 \times 10^{6} \mathrm{~m}^{2} \mathrm{~s}^{-1} \text { for seawater at } 12^{\circ} \mathrm{C}(\mathrm{Jumars} \\
\text { et al. 1993), near the sea-surface temperature } \\
\text { year-round at the Bodega Marine Lab }\end{array}$ \\
\hline$\rho$ & $\begin{array}{l}\text { Density of water, approximately } 1000 \mathrm{~kg} \mathrm{~m}^{-3} \text { for } \\
\text { freshwater in the flume, and } 1026 \mathrm{~kg} \mathrm{~m}^{-3} \text { for } \\
\text { seawater }\end{array}$ \\
\hline$A$ & $\begin{array}{l}\text { Cross-sectional area of the stipe, or of a specimen } \\
\text { in the materials testing machine }\end{array}$ \\
\hline$C_{d}$ & Drag coefficient \\
\hline$C_{m}$ & Inertial coefficient \\
\hline$D$ & Instantaneous drag \\
\hline$E$ & Elastic modulus of algal tissue \\
\hline$F$ & Tenacity \\
\hline$L$ & $\begin{array}{l}\text { Length from holdfast to thallus center of mass, or } \\
\text { of a specimen in the materials testing machine }\end{array}$ \\
\hline 1 & Total thallus length \\
\hline$k$ & Force constant of the spring \\
\hline$m$ & Mass of alga \\
\hline $\operatorname{Re}$ & Reynolds number, $R e=u l / v$ \\
\hline$R$ & Acceleration reaction \\
\hline$S$ & Projected area of alga \\
\hline$T$ & $\begin{array}{l}\text { Maximum tension on the stipe and holdfast calcu- } \\
\text { lated by the model given a set of flow conditions }\end{array}$ \\
\hline$t$ & Time \\
\hline$u$ & Flow velocity \\
\hline$V$ & Volume of alga \\
\hline$x$ & Position of alga \\
\hline
\end{tabular}

$$
R=\rho C_{m} V\left(\frac{\mathrm{d} u}{\mathrm{~d} t}-\frac{\mathrm{d}^{2} \boldsymbol{x}}{\mathrm{d} t^{2}}\right)
$$

where $C_{m}$ is the dimensionless inertial coefficient, $V$ is the volume of the thallus, and $\mathrm{d} u / \mathrm{d} t$ and $\mathrm{d}^{2} \mathrm{x} / \mathrm{d} t^{2}$ are the instantaneous accelerations of the water and of the mass, respectively. The tension in the chain is given by

$$
T=-k(|x|-L) \cdot[H(x-L)-H(-x-L)]
$$

where $k$ is the stiffness of the spring, and $L$ is the length of the thallus from the holdfast to the center of mass. The discontinuous nature of the tension in the chain is incorporated using a Heaviside step function, $H(n)$, which specifies that tension in the spring only occurs when the chain is extended (i.e. when there is no slack in the chain). Thus, the entire model reads:

$$
m \frac{\mathrm{d}^{2} x}{\mathrm{~d} t^{2}}=D+R+T
$$

Morphological measurements. Parameter values for Pelvetiopsis limitata were estimated in the following ways: On a near-monthly basis for about $2 \mathrm{yr}, 25$ P. limitata (Fig. 1A) were randomly collected from a $10 \mathrm{~m}$ transect haphazardly placed along a fullyexposed section of rocky shore at the Bodega Marine Laboratory in northern California. This transect ran parallel to the shore, through the center of 
P. limitata's tidal range. Each collected thallus was blotted dry in a paper towel, and $m$ was recorded to the nearest $0.01 \mathrm{~g}$ on a Mettler PB1502 balance. Cross-sectional area of the stipe $(A)$ and the attachment to the rock were estimated as the area of an ellipse, with the major and minor axes measured to the nearest $0.01 \mathrm{~mm}$ with digital calipers. P. limitata is nearly neutrally buoyant, so algal volume was defined as $V=m \times \rho$ (as in Gaylord et al. 1994). Total thallus length, 1 , from the bottom of the holdfast to the tip of the longest branch, was measured to the nearest $\mathrm{mm}$ with a ruler. When compacted in flow, this dichotomously-branching species resembles a cone with the base at the branch tips and the apex at the holdfast. Thus, the distance $L$ of the center of mass of an alga from the holdfast was defined as being the same distance as the center of mass of a cone (Fig. 1C) of the same overall volume and length is from the apex $(L=0.8 \times 1)$. Other morphological parameters measured are described further below.

Material properties of thallus tissue. The force required to stretch a spring is directly proportional to the distance that the spring is extended. Spring stiffness $(k)$ of thallus tissue for the model was determined on Pelvetiopsis limitata, freshly collected at random in the field, using an Instron 1122 Universal Testing Machine. During the tests, all but the longest branch of an alga were removed and the specimen was fastened in the machine with rubber-lined clamps which tightly held the specimen without damaging the tissue. The machine pulled the tissue along the axis of the branch at a constant rate of $1.67 \mathrm{~mm} \mathrm{~s}^{-1}$ (strain rate between 0.025 and $0.181 \mathrm{~s}^{-1}$, with a mean of $0.060 \mathrm{~s}^{-1}$ ), while simultaneously measuring the force required to impose that strain. The slope of the resulting plot of force as a function of $k$ is related to the size and material properties of the specimen:

$$
k=\frac{E A}{L}
$$

where $E$ is the elastic modulus of the tissue, a measure of stiffness defined as the slope of a stress-strain curve, $A$ is the initial cross-sectional area and $L$ is the original length of the specimen. The resulting elastic modulus of algal tissue was used in Eq. (5), with regressions describing the scaling of $A$ and $l$ of whole individuals, to find a relationship between thallus length and $k$ of intact algae. The results of this regression of the form $\left(k=a m^{b}\right)$ were used in Eq. (3) to predict the tension in the stipe and holdfast as the model was run.

Drag and inertial coefficients, and flow beneath waves. Steady-state drag coefficients $\left(C_{d}\right)$ for Pelvetiopsis limitata were calculated from measurements of the hydrodynamic force on individual thalli exposed to flow in a recirculating flume. The working section of the flume was $45 \mathrm{~cm}$ high, $35 \mathrm{~cm}$ wide, and $2.4 \mathrm{~m}$ long (see description in Martinez 2001). Force measurements were made using a single-axis strain-gage force transducer, placed in the flume so that the bottom of algal holdfasts were level with a false bottom in the working section. Flow speed in the flume was measured to the nearest $0.01 \mathrm{~cm} \mathrm{~s}^{-1}$ with an Acoustic Doppler Velocimeter, with the sampling volume of the probe within $5 \mathrm{~cm}$ upstream of the alga and at midthallus height in still water. Force and velocity measurements on each alga $(\mathrm{n}=21$ thalli) were recorded at $10 \mathrm{~Hz}$ for $10 \mathrm{~s}$ using 7 steady flow speeds $(u=0.25$, $0.45,0.65,0.85,1.0,1.15$, and $1.2 \mathrm{~m} \mathrm{~s}^{-1}$ ). The average force and velocity during each $10 \mathrm{~s}$ recording were used in Eq. (1) to calculate $C_{d}$ at each flow speed for each alga. The maximum projected area of thalli for these calculations ( $S$ in Eq. 1) was measured to the nearest $0.01 \mathrm{~cm}^{2}$ using images obtained by spreading algae flat on the bed of an image scanner, and a pixelcounting algorithm written in MATLAB (R13, MathWorks). For use in Eq. (4), a regression of $C_{d}$ as a function of Reynolds number $(R e=u l / v)$ was used to characterize $C_{d}$ as a function of flow velocity and algal mass. Note that using this convention, the reduction in projected area $(S)$ due to reconfiguration of the alga at higher flow speeds appears as a decrease in $C_{d}$ (i.e. in the drag equation, $S$ is kept constant and reconfiguration at higher flow velocities was accounted for by changes in $C_{d i}$ see Bell 1999). The value of the inertial coefficient for this species $\left(C_{m}=5.64\right)$ was an average value from measurements by Gaylord et al. (1994) and was assumed to be constant. For the purposes of the model, seaward/shoreward flow velocity beneath broken waves, $u(t)$, was characterized as a sine function (but see caveats in 'Discussion') of which the peak velocity and wave period were adjusted, to explore the consequences of seasonal changes in wave conditions.

Flexibility and scaling of tension with thallus size. To determine the influence of thallus flexibility on the scaling of peak tension with thallus size, the model was run using conditions that either simulated an alga that could deform to become more streamlined in flow, but with a stationary center of mass, or conditions simulating a flexible alga allowed to move with the flow beneath the waves. To simulate non-moving algae, terms allowing for motion of the alga in Eqs. (1), (2) \& (4) (i.e. those involving $x$ ) were set to zero, leaving the tension in the stipe to equal the instantaneous sum of $C_{d}$ and $R$ on the motionless thallus. To simulate flexible algae, Eqs. (1) to (4) were used in their entirety. Simulations were run using algae over a range of $m$ values, and over variety of wave periods and peak $u$ values, to examine the scaling of predicted stipe tensions with algal size as a function of wave conditions. 
Algal tenacity. The force required to break or dislodge all individual algae collected was measured to the nearest $0.25 \mathrm{~N}$ at the time of collection using a spring scale modified to record maximum forces (Bell \& Denny 1994). The spring scale was calibrated by measuring the force required to extend it over a distance using an Instron 1122 Universal Testing Machine. Individuals were collected using a string lasso wrapped around the thallus and pulled parallel to the substratum until failure occurred at the holdfast or stipe. The reading on the scale measured the force required to dislodge (holdfast failure) or break (stipe failure) each alga. Algae that broke due to abrasion or stress-concentration at the string lasso were discarded. Any portions of an alga left on the rock after breaking were collected for morphological measurements in the laboratory.

Predicting seasonal dislodgement. Seasonal dislodgement of algae in the field was predicted with the model using an analysis described by Gaylord et al. (1994). Tenacity of an alga of any given size may be highly variable across the population, due to differences in algal strength and substratum quality. This natural variation was used to predict the proportion of algae, as a function of size, that would be strong enough to survive the largest wave expected during a given month.

The tension $(T)$ imposed on the stipe and holdfast of algae over a range of thallus sizes by the largest wave expected each month during an average year was calculated using the model. Peak flow velocities experienced on the shore each month were estimated using offshore buoy data from 1981 to 2001 (NOAA National Data Buoy Center \#43016, Bodega Bay buoy), and a technique described by Denny \& Gaines (1990) and Denny (1991). The average dominant wave period each month was also taken from buoy data. Using these flow parameters to characterize $u(t)$ as a sine function, numerical simulations using Eq. (4) were used to calculate the largest tensile force imposed on an alga each month in an average year as a function of thallus size.

To determine the probability that algae would be dislodged each month by the maximum predicted forces, the tenacities of collected algae were expressed as the ratio of the measured tenacity to the expected value calculated using a regression of tenacity as a function of mass $\left(F=a m^{b}\right)$. These relative tenacities were ranked and fit to a modified Weibull model (details in Gaylord et al. 1994), which yielded a probability distribution that allowed calculations of the proportion of algae of a given size that would be expected to possess a breaking strength greater than the tensile force imposed on their stipe and holdfast by a given wave.
Field surveys and reproductive effort. To monitor the fate of individual algae in the population over the study period, digital photographs of 4 permanent $0.1 \mathrm{~m}^{2}$ quadrats were taken on each trip. These quadrats were haphazardly established in an area about $5 \mathrm{~m}$ shoreward of the sampling transect, near the center of the tidal range of Pelvetiopsis limitata. To determine the most common mode of failure of algae broken or dislodged by waves in the field, collections of broken and dislodged individuals were conducted in November 2003 and January 2004 on a sandy beach adjacent to the study area. During these surveys, field assistants started on one end of the sandy beach and for $2 \mathrm{~h}$ carefully sifted through all of the wrack and debris they came across as they made their way along the shore. Branch fragments and whole individuals of $P$. limitata were collected whenever encountered and taken to the laboratory to determine the mode of failure, either dislodgement of the entire holdfast or breakage at the stipe or branches.

To examine seasonal patterns of reproduction, the reproductive effort of every alga collected each month was recorded as the proportion of thallus branches on each individual containing receptacles.

Statistical analyses. All statistical analyses were performed using MATLAB. Ordinary Least Squares (OLS) regressions, corrected for log transformation (Sprugel 1983), were used to fit allometric equations, because in every case, independent variables were measured with techniques involving much smaller measurement error than those used to obtain values of the dependent variable (Rayner 1985).

\section{RESULTS}

\section{Material properties of thallus tissue}

Mean E of Pelvetiopsis limitata tissue was $0.77 \mathrm{MN}$ $\mathrm{m}^{-2}$, but highly variable between individuals $(\mathrm{SD}=$ $0.43 \mathrm{MN} \mathrm{m}^{-2}$ ). $E$ was not a function of algal size; algae were slightly stiffer during the summer $(p>0.18$ for size, and $\mathrm{p}<0.02$ for season; ANCOVA with $E$ as a function of size covarying with collection date; $\mathrm{n}=55$ ). Plots of stress and strain were nearly linear at the strain rate used $\left(1.67 \mathrm{~mm} \mathrm{~s}^{-1}\right)$, and individuals pulled more slowly (at 0.167 and $0.0167 \mathrm{~mm} \mathrm{~s}^{-1}$ ) showed no detectable difference in $E$ (but see concluding caveats). Thus, a constant $E$ (independent of thallus size, strain, and strain rate), and regressions of the measurements of area $\left(A=0.14 \times m^{0.51}, \mathrm{n}=284, \mathrm{r}^{2}=\right.$ 0.41) and length $\left(L=4.63 \times m^{0.31}, \mathrm{n}=284, \mathrm{r}^{2}=0.65\right)$ were used in Eq. (5) to obtain an estimate of $k$ as a function of $m$, for use in the model. 


\section{Drag coefficient}

A plot of $C_{d}$ as a function of $R e$ for force measurements in unidirectional flow in the flume is shown in Fig. 2. The resulting regression, $C_{d}=318 \times R e^{-0.78}$ $\left(\mathrm{r}^{2}=0.82\right)$, was used in the model simulations to calculate $C_{d}$ in seawater of an alga as a function of $u$ and $l$. According to the fit shown in Fig. 2, $C_{d}$ does not decrease appreciably at large Reynolds numbers ( $R e>$ 2.5), limiting the consequences of extrapolation (Gaylord et al. 1994, but see Bell 1999). Reynolds numbers above this point are produced by peak velocities typical of those beneath large waves in the rocky intertidal zone (>2.5 $\mathrm{m} \mathrm{s}^{-1}$; e.g. Gaylord 1999); these velocities are out of the range of the flume used to make these measurements.

\section{Flexibility and scaling of tension with thallus size}

The influence of thallus flexibility on $T$ experienced by algae as a function of wave period, peak $u$, and $m$ is shown in Fig. 3. To create these plots, model predictions of peak $T$ across thallus sizes at each wave period and peak $u$ tested were fit to a power function, $T$ $=a \mathrm{~m}^{b}$. In this equation, the leading coefficient $a$ is an indication of the absolute magnitude of peak tension, and $b$ demonstrates how peak tension scales with $m$.

The simulations showed that the peak $T$ in the stipe of a non-moving, rigid alga scaled with a mass exponent $b$ near 0.70 (Fig. 3A). In this case, the longer periods typical of larger waves caused $b$ to decrease. In contrast, simulations of flexible algae that could move back and forth with the flow resulted in $b>0.85$ in most situations, becoming even larger with longer wave periods (Fig. 3B).

The coefficient indicating the magnitude of these forces (a) increased with peak $u$ in rigid algae (Fig. 3C), but it was independent of wave period. When thallus flexibility was included, even for a species as small as Pelvetiopsis limitata, the magnitude of peak $T$ (directly proportional to a) was much larger than in rigid algae under the same conditions (Fig. 3D). In addition, flexibility also resulted in peak $T$ becoming a strong function of wave period, with shorter periods leading to larger forces.

\section{Scaling of tenacity}

Most algae (84\%) were ripped off of the rock at the holdfast, rather than breaking at the stipe, when pulled by the spring scale $(n=285)$. Similarly, $74 \%$ of Pelve-

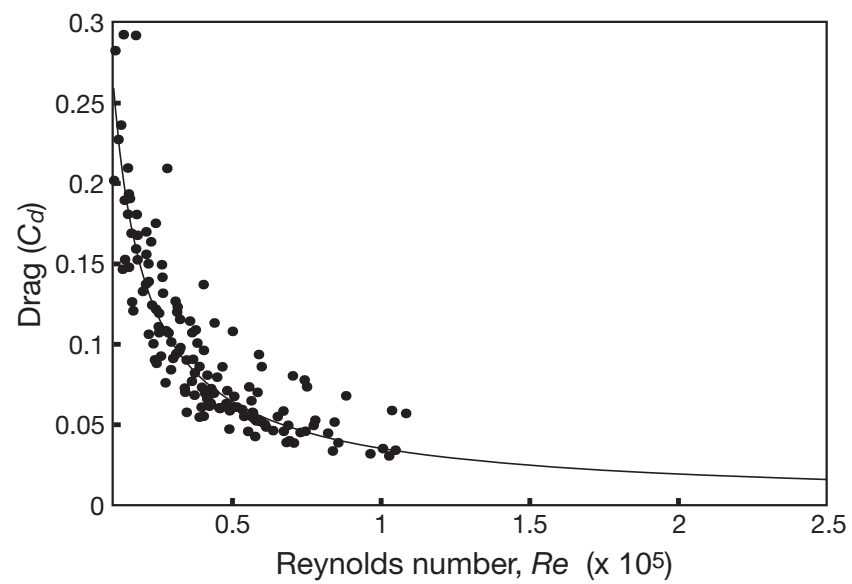

Fig. 2. Drag coefficient $\left(C_{d}\right)$ as a function of Reynolds number $(R e)$ in a unidirectional flume. Data pooled from 21 algae and fit with an OLS regression; $C_{d}=318 \times R e^{-0.78}\left(\mathrm{r}^{2}=0.82\right)$
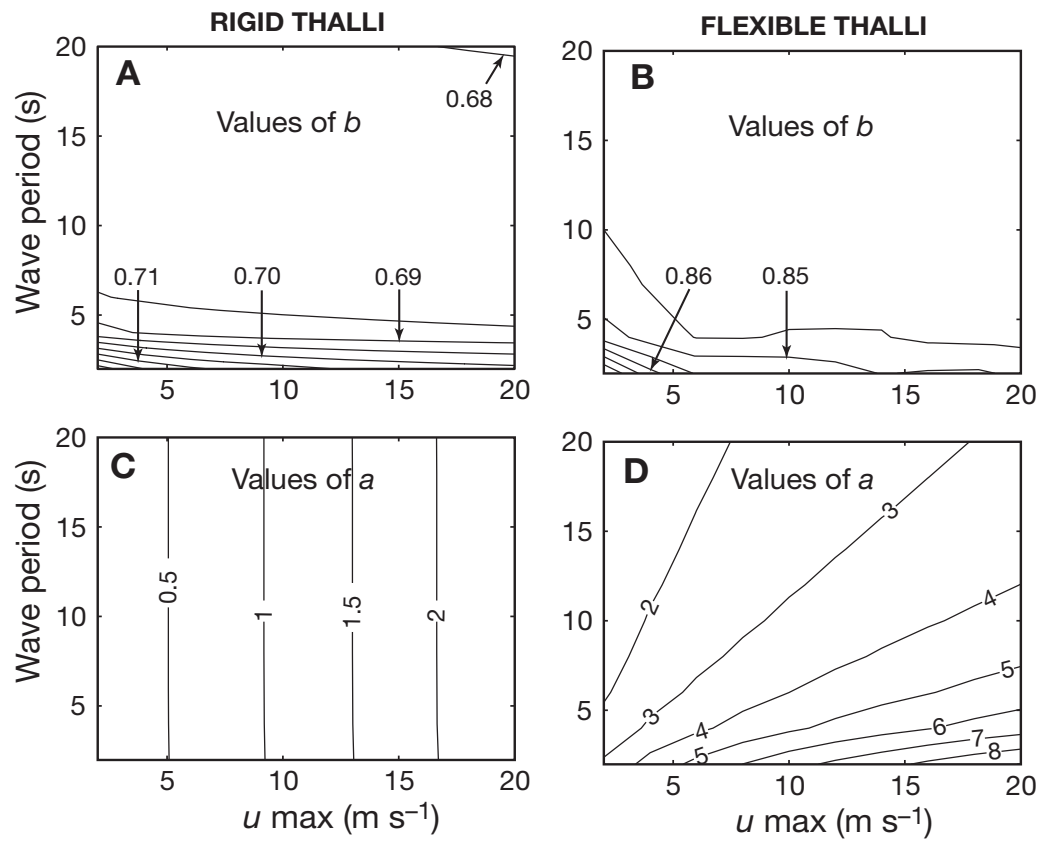

Fig. 3. Pelvetiopsis limitata. Values of maximum tension $(T)$ as a function of size $(m)$, over a range of peak flow velocities $(u)$ and wave periods, fit to the equation $T=a m^{b}$. Contour lines: resulting in the same scaling coefficient ( $a$ or $b$ ). (A) Values of $b$ as a function of wave period and $u$ when only drag $\left(C_{d}\right)$ and acceleration reaction $(R)$ on a rigid thallus are considered; $b$ decreases as wave period increases. (B) Values of $b$ when the complete model, including algal flexibility and motion, is used; $b$ increases as wave period increases. (C) Values of $a$ as a function of wave period and $u$, of a rigid alga; $a$ is independent of wave period and increases with $u$. (D) Values of $a$ using the complete model; a depends on both wave period and $u$, and its absolute values are higher than in (C), meaning that motion of the alga increases the tension experienced by stipe and holdfast 
tiopsis limitata fragments found during beach surveys were complete individuals with holdfast attached ( $\mathrm{n}=$ 95), indicating that this species is usually torn off at the holdfast under natural conditions. Quadrat photographs near the study site taken each month showed little evidence of branch fragmentation or the tattering of thalli (but see Blanchette 1997 for tattering in a larger, related species). Thus, the spring scale appeared to correctly reproduce the mode of failure most common in natural disturbance events. The relationship between algal size and $T$ did not change with the seasons during this study (ANCOVA with $T$ as a function of $m$ covarying with collection date; $p>0.05$ ). Thus, tenacity measurements (which include both dislodgement of the holdfast and breakage of the stipe) for all months were pooled and the results are shown in Fig. 4.

\section{Seasonal dislodgement}

The model predicted that large individuals were much more likely to be ripped from the rocks than smaller ones in every month (a representative month is shown in Fig. 5). Fig. 6 shows the mass of the 75th percentile of calculated survivors when exposed to the waves expected each month during an average year. This figure shows that during the winter, when waves are larger, smaller algae are more likely to be dislodged than during the summer and early fall; this implies that algae will be smaller during the winter and larger during the summer.

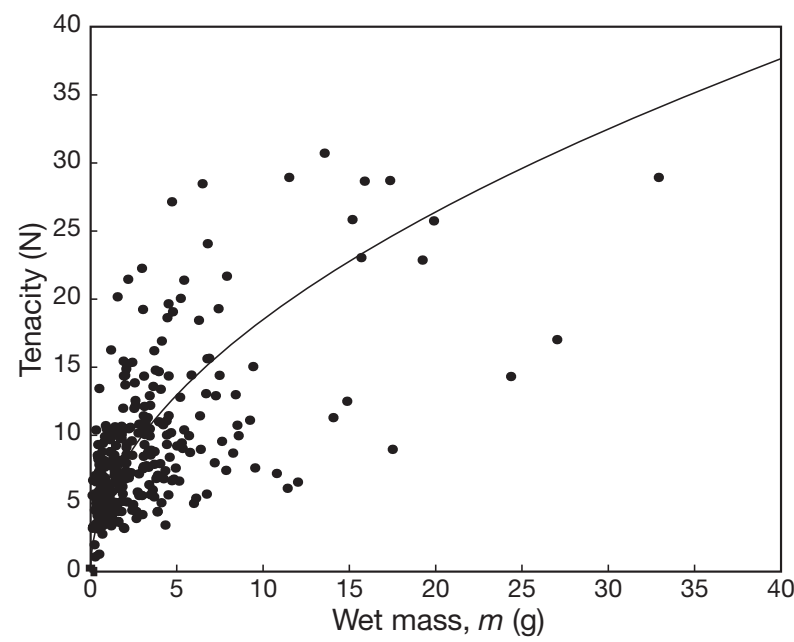

Fig. 4. Pelvetiopsis limitata. Tenacity, i.e. breaking strength, of algae as a function of size (mass, $m$ ). Regression coefficients did not vary throughout the year (see 'Results') with $F=6.49 \times m^{0.31}\left(\mathrm{r}^{2}=0.37, \mathrm{n}=284\right)$ resulting from the pooled data. The large spread around the curve reflects the high variability of tenacity in algae in the field

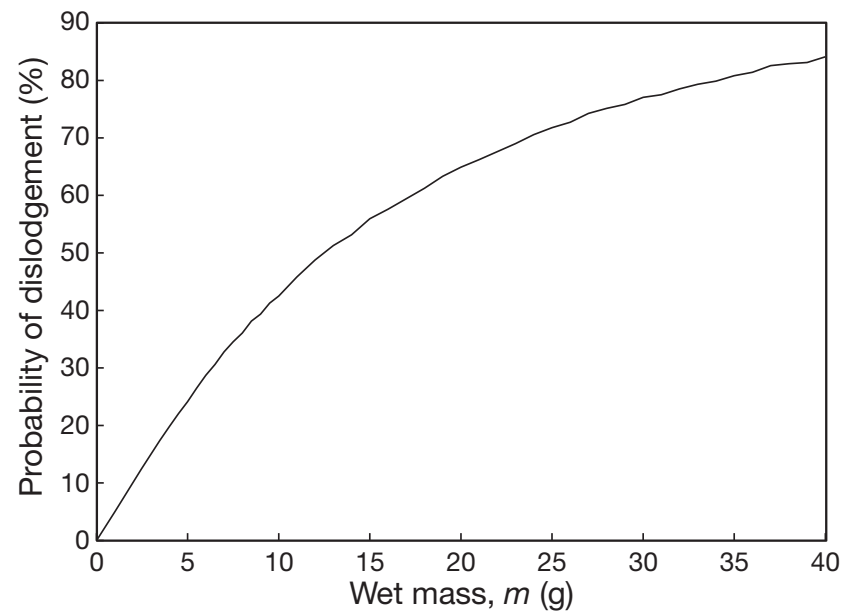

Fig. 5. Pelvetiopsis limitata. Estimated probability of dislodgement at wave-exposed sites on the Bodega Marine Reserve as a function of thallus mass $(m)$ during an average January. In all months the probability of dislodgement increased with size, but the slope of the curve varied with seasonal wave conditions

\section{Thallus size and reproduction}

The size distribution of the Pelvetiopsis limitata population in the field changed markedly over time (Fig. 7A). Median size was small during late fall and winter, and became larger as algae grew during the early summer; size peaked during late summer and early fall, and fell again during late fall. This pattern was more pronounced with the largest individuals in the population (e.g. 75th percentile in Fig. 7A).

Reproductive effort showed a seasonal pattern similar to thallus size, with reproductive receptacles being abundant during the late summer and early fall (Fig. 7B).

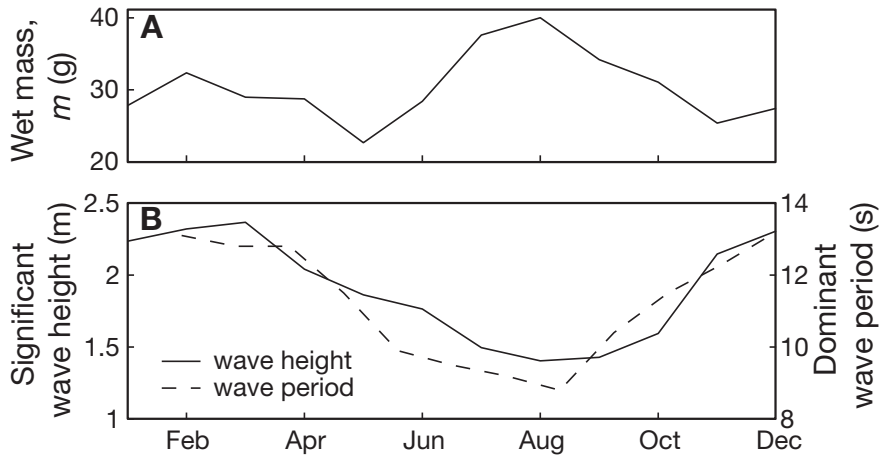

Fig. 6. Pelvetiopsis limitata. (A) Mass ( $m$ ) of the 75th percentile of predicted survivors of the largest wave expected during each month of an average year at the Bodega Marine Reserve (i.e. $>75 \%$ of algae larger than the values plotted are predicted to become dislodged); larger algae survive the smaller waves during the summer. (B) Median significant wave height and dominant wave period between 1981 and 2001 at the Bodega Bay buoy (NOAA National Data Buoy Center \#43016) 

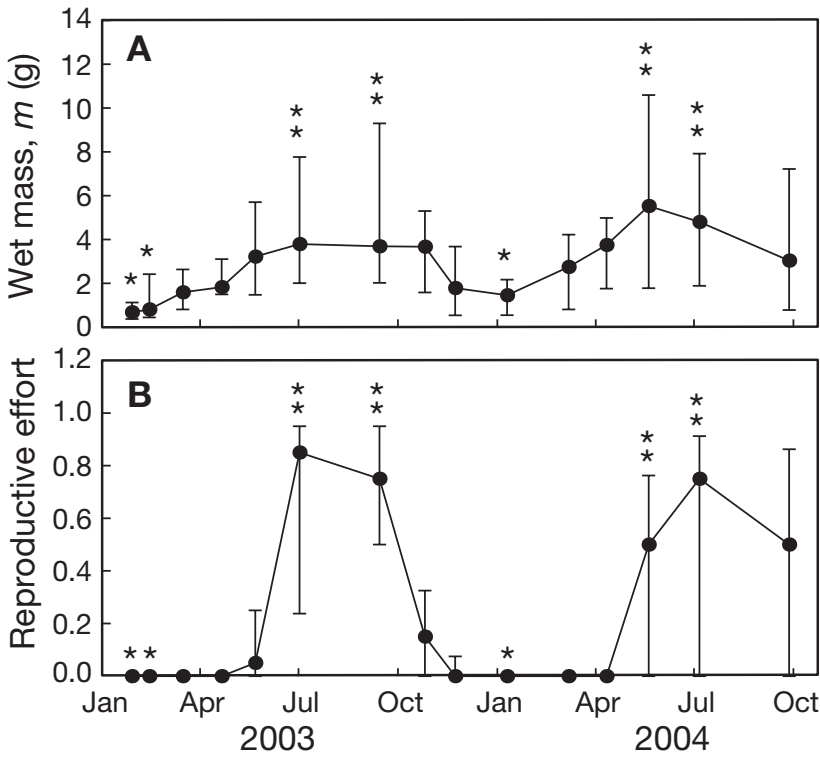

Fig. 7. Pelvetiopsis limitata. (A) Median wet mass $(m)$ of algae collected each month. (B) Median reproductive effort (proportion of branches with receptacles). Error bars: 25th and 75th percentiles. Both $m$ and reproductive effort of the population changed over time (Kruskall-Wallis, $\mathrm{p}<0.005$ ). Data marked with 1 and 2 asterisks are significantly different from each other (Tukey's HSD, p < 0.05)

\section{DISCUSSION}

\section{Consequences of thallus flexibility}

Fig. 3A,B indicates that when thallus motion and flexibility are taken into account, peak $T$ scales with a much larger mass exponent $(b)$ than if algae were simply deformable but rigid bodies. In Pelvetiopsis limitata, neither peak $u$ nor wave period had a strong effect on $b$. The leading coefficient $(a)$ of these regressions was also much larger in flexible algae (Fig. 3C,D). Flexible thalli that were able to move beneath the waves experienced large inertial forces when the algae were jerked to a halt at the end of their stipe while they moved back and forth with each seaward and shoreward excursion of flow. These inertial jerks increased peak tensions for all thalli, most severely for larger individuals. As expected, a did not depend on wave period for rigid thalli (Fig. 3C). However in flexible algae, wave period determined the timing of peak $u$, and consequently the largest imposed drag force, relative to the instant when algae in motion were jerked to a stop. Shorter wave periods increased this combined force, leading to even larger values of $T$ and $a$. The flexibility of very long seaweeds (e.g. Koehl 1986) decreases the tensions imposed on their stipe and holdfast by allowing the plant to move along with the water when flow speeds are the highest. $P$. limitata is small, however, relative to the excursions of water beneath broken waves, and does not benefit from this flexibility. In contrast, the flexibility of $P$. limitata dramatically increases the inertial force and resulting tension in the stipe and holdfast when algae are whipped back and forth beneath the waves.

\section{Waves impose an upper limit on thallus size}

Stipe tension under large waves increases faster with $m$ than does tenacity, as indicated by their scaling exponents (Figs. 3C \& 4), which suggests that a mechanical size limit exists in Pelvetiopsis limitata. In addition, the model predictions in Fig. 5 show that the probability of dislodgement increases dramatically with $m$ over the range of algal sizes existing in the field. Seasonal variation in wave height and period modulate the forces imposed on algae, leading to seasonal changes in the potential limit on algal size (Fig. 6), with larger algae expected to survive the weaker waves during summer months. Measurements of algal size throughout the year confirmed this prediction (Fig. 7A), as algae in the field were larger during the summer and smaller during the winter. The model predicts that the greatest danger to very large algae occurs in May, due to the combination of wave height and period (Fig. 6), but field collections revealed that most of these endangered individuals would already have been dislodged by waves during the previous winter (Fig. 7). These observations are consistent with a mechanical limit on the size of $P$. limitata that tracks seasonal changes in wave conditions. Due to the increase of both the absolute magnitude $(a)$ and the mass exponent $(b)$ of the allometric equation describing $T$ when algal flexibility is taken into account (Fig. 3), thallus flexibility actually makes the upper limit on thallus size much lower than if the species were rigid.

\section{Life-history strategy and size limitation}

Pelvetiopsis limitata reproduced during the late summer and early fall, the time of year when individuals of this species were also the largest (Fig. 7). During months when reproduction occurred, larger individuals generally had reproductive receptacles on a higher proportion of their branches, and their size allowed these large individuals to have a much higher absolute number of reproductive receptacles than did small individuals. Therefore, large thallus size is advantageous for gamete production. Model results showed that those large individuals that contributed disproportionately to reproductive effort in the population during the summer are less likely to survive the waves of winter (Fig. 6). Field observations of thallus size during 
the year (Fig. 7) confirmed that these large algae were generally dislodged during the fall. The minority of individuals that break at the stipe or leave a portion of the holdfast attached to the rock may have the ability to regenerate, as do other fucoid species (McCook \& Chapman 1992). Reproduction during the summer and early fall allows this species to maximize reproductive output by growing large during the summer when waves are small, releasing gametes before the probability of dislodgement increases in the winter.

\section{Caveats and conclusions}

The present model is useful for producing broad, qualitative predictions regarding the consequences of flexibility and the potential for mechanical size limitation in intertidal organisms. These predictions provide a theoretical basis for exploring the consequences of body size, and strategies for growth and reproduction, in seasonally varying habitats. Several of the assumptions made here, however, diminish the value of this model toward providing accurate, site-specific predictions regarding disturbance events.

While flow beneath broken waves follows the pattern of a bi-directional sine function used here on a gross scale, flow can also be 3-dimensional, very turbulent, and highly dependent on local topography (Gaylord 1999). Further measurements of flow and the forces imposed on organisms in this habitat (e.g. Koehl 1977, Gaylord 2000) are needed to reveal the mechanical consequences of the temporal and spatial complexity of flow in the surf zone for organisms on the shore. In addition, while generally reproducing seasonal patterns of wave-driven flow fairly well, the use of the 'statistics of extremes' (Denny \& Gaines 1990, Denny 1991) with offshore buoy data to predict peak velocities under large waves on the shore is often a poor estimate of actual flow conditions at a site (Gaylord 1999, Helmuth \& Denny 2003), largely because of underestimating peak flow velocities beneath waves. Improving estimates of flow in the field would provide better site-specific predictions of algal dislodgement. Increasing peak $u$ in the model to values much higher than those predicted from offshore buoy data changed quantitative predictions by increasing dislodgement, but did not alter the qualitative conclusions regarding its scaling with algal size.

$C_{d}$ at the very high $u$ values beneath breaking waves were extrapolated from measurements at lower flow speeds. While the resulting regression predicted that thallus reconfiguration had a negligible effect on $C_{d}$ at high velocities, a precise relationship between $C_{d}$ and $R e$, measured over the entire range of possibilities, may lead to more accurate estimates of the drag forces imposed on algae (Bell 1999). Furthermore, $C_{m}$ was assumed to be independent of thallus size in this study. While $C_{m}$ is theoretically constant for rigid bodies (Gaylord et al. 1994), reconfiguration, which may vary with thallus size and shape, can alter the added mass of a flexible object. While the $R$ (Eq. 2) generally contributed little to the overall force on these small algae, incorporating any size dependence of $C_{m}$ may lead to small differences in the numerical calculations.

A relatively simple mechanical model with springlike material properties likely describes only major trends in the scaling of maximum forces with thallus size. A more complex model that includes the dependence of algal material properties on strain and strain rate (Hale 2001), would be required for a more precise analysis. Tests of the model including the small changes in stiffness identified by the statistically insignificant $(\mathrm{p}>0.05)$ trend of increasing $E$ with size, and the statistically significant $(p<0.005)$ trend of higher stiffness during the summer, changed the numerical results little, and did not alter the major conclusions.

\section{Conclusions}

The present model provides a useful tool for studying the effect of flexibility on the magnitude and scaling of forces imposed on organisms in the rocky intertidal zone. Thallus flexibility in Pelvetiopsis limitata increased the tension experienced in the stipe and holdfast, particularly in large individuals. Field studies corroborated that the probability of wave-induced dislodgement increases dramatically with thallus size, so that size appears to be mechanically limited in this species. Seasonal patterns of wave height made the overall risk of dislodgement of large algae highest during the winter, a pattern which was also confirmed in field observations. P. limitata reduces the reproductive consequences of size limitation by growing large during the summer when wave conditions permit, and reproducing at this large size. By this timing of reproduction, $P$. limitata maximizes reproductive output. Thus, $P$. limitata provides an example of a species with a life-history strategy that mitigates the consequences of seasonal disturbance events, even while possessing a mechanical structure that increases the severity of these events.

Acknowledgements. I thank S. Valencia, Z. Morrison, A. Cook, J. Woodruff, H. Stewart and C. Wolcott for assistance in the field. J. Strother, T. Powell and M. Stacey provided advice while coding and analyzing data from the model. Discussions with M. Koehl greatly improved this study and the manuscript. Four anonymous reviewers provided helpful comments during the review process. Funding for this study was provided by the Department of Integrative Biology at the University of California at Berkeley, Sigma Xi, the University of California Natural Reserve System, and NSF grants OCE9907120 and OCE-0241447 to M. Koehl. 


\section{LITERATURE CITED}

Abbott IA, Hollenberg GJ (1976) Marine algae of California. Stanford University Press, Palo Alto, CA

Bell EC (1999) Applying flow tank measurements to the surf zone: predicting dislodgement of the Gigartinaceae. Phycol Res 47:159-166

Bell EC, Denny MW (1994) Quantifying 'wave exposure': a simple device for recording maximum velocity and results of its use at several field sites. J Exp Mar Biol Ecol 181: 9-29

Blanchette CA (1997) Size and survival of intertidal plants in response to wave action: a case study with Fucus gardneri. Ecology 78(5):1563-1578

Ceccarelli S (1984) Plant responses to water stress: a review. Genet Agrar 38(1):43-74

Connell JH (1972) Community interactions on marine rocky intertidal shores. Annu Rev Ecol Syst 3:169-192

Dayton PK (1971) Competition, disturbance and community organization: the provision and subsequent utilization of space in a rocky intertidal community. Ecol Monogr 41(4): 351-389

Denny MW (1985) Wave forces on intertidal organisms: a case study. Limnol Oceanogr 30:1171-1187

Denny MW (1991) Biology, natural selection and the prediction of maximal wave-induced forces. S Afr J Mar Sci 10: 353-363

Denny MW (1995) Predicting physical disturbance: Mechanistic approaches to the study of survivorship on waveswept shores. Ecol Monogr 65:371-418

Denny MW (1999) Are there mechanical limits to size in wave-swept organisms? J Exp Biol 202:3463-3467

Denny MW, Gaines SD (1990) On the prediction of maximal intertidal wave forces. Limnol Oceanogr 35:1-15

Denny M, Gaylord B (2002) The mechanics of wave-swept algae. J Exp Biol 205:1355-1362

Denny MW, Daniel TL, Koehl MAR (1985) Mechanical limits to size in wave-swept organisms. Ecol Monogr 55:69-102

Denny M, Gaylord B, Helmuth B, Daniel T (1998) The menace of momentum: dynamic forces on flexible organisms. Limnol Oceanogr 43:955-968

Friedland MT, Denny MW (1995) Surviving hydrodynamic forces in a wave-swept environment: consequences of morphology in the feather boa kelp, Egregia menziesii (Turner). J Exp Mar Biol Ecol 190:109-133

Gardner NL (1913) New Fucaceae. Univ Calif Publ Bot 4: $317-374$

Gaylord B (1999) Detailing agents of physical disturbance: wave-induced velocities and accelerations on a rocky shore. J Exp Mar Biol Ecol 239:85-124

Gaylord B (2000) Biological implications of surf-zone flow complexity. Limnol Oceanogr 45:174-188

Editorial responsibility: Otto Kinne (Editor-in-Chief), Oldendorf/Luhe, Germany
Gaylord B, Blanchette CA, Denny MW (1994) Mechanical consequences of size in wave-swept algae. Ecol Monogr $64: 287-313$

Hale B (2001) Macroalgal materials: foiling fracture and fatigue from fluid forces. PhD dissertation, Stanford University, Palo Alto, CA

Harger JRE (1970) The effect of wave impact on some aspects of the biology of sea mussels. Veliger 12(4):401-414

Helmuth B, Denny MW (2003) Predicting wave exposure in the rocky intertidal zone: Do bigger waves always lead to larger forces? Limnol Oceanogr 48(3):1338-1345

Koehl MAR (1977) Effects of sea anemones on the flow forces they encounter. J Exp Biol 69:87-105

Koehl MAR (1984) How do benthic organisms withstand moving water? Am Zool 24:57-70

Koehl MAR (1986) Seaweeds in moving water: Form and mechanical function. In: Givnish TJ (ed) On the economy of plant form and function. Cambridge University Press, Cambridge, p 603-634

Koehl MAR (1998) The quirks of jerks. Nature 396:621-623

Koehl MAR (1999) Ecological biomechanics of benthic organisms: life history, mechanical design and temporal patterns of mechanical stress. J Exp Biol 202:3469-3476

Koehl MAR, Wainwright SA (1977) Mechanical adaptations of a giant kelp. Limnol Oceanogr 22:1067-1071

Lewis JR (1968) Water movements and their role in rocky shore ecology. Sarsia 34:13-36

Martinez MM (2001) Running in the surf: hydrodynamics of the shore crab Grapsus tenuicrustatus. J Exp Biol 204: 3097-3112

Paine RT (1976) Biological observations on a subtidal Mytilus californianus bed. Veliger 19:125-130

Paine RT, Levin SA (1981) Intertidal landscapes: disturbance and the dynamics of pattern. Ecol Monogr 51(2):145-178

Rayner JMV (1985) Linear relations in biomechanics: the statistics of scaling functions. J Zool (Lond) 206:415-440

Santelices B, Castilla JC, Schmiede P (1980) Comparative ecology of Lessonia nigrescens and Durvillaea antarctica (Phaeophyta) in central Chile. Mar Biol 59:119-132

Sebens KP (1987) The ecology of indeterminate growth in animals. Annu Rev Ecol Syst 18:371-408

Sousa WP (1979) Disturbance in marine intertidal boulder fields: the nonequilibrium maintenance of species diversity. Ecology 60:1225-1239

Sousa WP (1984) Intertidal mosaics, patch size, propagule availability, and spatially variable patterns of succession. Ecology 65:1918-1935

Sprugel DG (1983) Correcting for bias in log-transformed allometric equations. Ecology 64:209-210

Stearns SC (1976) Life history tactics: a review of the ideas. Q Rev Biol 51:3-47

Whelan RJ (1995) The ecology of fire. Cambridge University Press, Cambridge

Submitted: January 4, 2007; Accepted: April 24, 2007

Proofs received from author(s): May 17, 2007 